\title{
Vuelos traumáticos, padres imaginarios y burguesía neurótica
}

\author{
Relatos salvajes | Damián Szifrón | 2014
}

\section{Frédéric Conrod"}

\author{
Florida Atlantic University
}

Recibido 14 de julio 2017; aceptado: 8 de septiembre 2017

\begin{abstract}
Resumen
La película Relatos salvajes de Damián Szifrón ha marcado la historia del cine argentino desde el día de su estreno, y no sólo porque ofrece una mirada íntima hacia un fondo agresivo de una cultura que auto-reprimió sus traumas sino también porque todas las culturas occidentales encuentran en esta colección de relatos anecdóticos un reflejo ético de sus propias heridas. El hecho de que el director español Pedro Almodóvar quisiera producir la obra del joven argentino habla mucho sobre la necesidad de usar el séptimo arte como terapia de choque donde el público se enfrenta con su naturaleza salvaje y primitiva (el Id freudiano), escondida en su profundo interior por siglos de represión acumulada. Este artículo se concentra en la figura del padre imaginario, definida por el psicoanalista francés Jacques Lacan, para explorar cómo se encadenan los capítulos de la película en su afán de presentar los traumas culturales, sus causas históricas e individuales, y la neurosis que se concentra alrededor de la clase burguesa que determina en Argentina - como en la mayoría del Occidente - el comportamiento social. Asimismo, y siguiendo el pensamiento teórico del filósofo esloveno Slavoj Žižek, se observará cómo en cada corto que compone Relatos salvajes se descomponen los síntomas éticos de una sociedad consciente de sus comportamientos neuróticos hasta reconocer que la explosión cómica de sus lados salvajes es la terapia más eficaz que le pueda ofrecer el cine.
\end{abstract}

Palabras clave: Szifrón | Relatos salvajes | Lacan | Žižek | Padre Imaginario | Argentina

\begin{abstract}
Damián Szifrón’s blockbuster Wild Tales came to the box office as a landmark in Argentinian cinema, not only because it reveals a deep gaze on the aggressive nature of a culture that self-repressed its traumas, but also because every Western culture can contemplate ethically its own scars in this collection of anecdotic tales. Only the fact that Spanish director Pedro Almodóvar would want to produce the work of his young Argentinian counterpart says a lot about the necessity to utilize cinema as a chock therapy where the audience confronts its own wild and primitive nature (The Freudian Id), hidden in its deep interior through centuries of accumulated repression. This article focuses on the figure of the imaginary father, as defined by French analyst Jacques Lacan, in order to explore how the chapters of the film form of chain that presents cultural traumas, historical and individual causes, as well as the neurosis surrounding the Argentinian bourgeoisie, usual ruler of social behavior in the majority of Western societies. In line with the recent work of Slovenian philosopher Slavoj Žižek, this research will observe how each chapter of Wild Tales decomposes the ethical symptoms of a society that is aware of its neurotic behaviors to the point that it acknowledges that comic explosions of its wild sides is the most efficient therapy that cinema can offer.
\end{abstract}

Key words: Szifrón | Wild Tales | Lacan | Žižek | Imaginary Father | Argentina

En la explosiva película del argentino Damián Szifrón, Relatos salvajes (2014), se descubren unos personajes enredados en situaciones que examinan la experiencia humana bajo una clara confusión ética e ideológica. Lo cual es inevitable dentro del mensaje de alarma social que quiere mandar esta obra: la sociedad argentina se vuelve primitiva, definitivamente, como única salida de sus traumas y su neurosis. Siguiendo el modelo narrativo medieval del Pentamerone italiano, el filme empieza con un corto introductorio seguido por cinco cortos más largos en forma de capítulos independientes. Cada uno de ellos se dedica a llevar el humor negro argentino a sus extremos, desde la Argentina rural a la urbana, desde la clase obrera a la alta burguesía. Con 449.292 espectadores es a la fecha el filme argentino más visto en la historia durante su primer fin de semana de exhibición. También se convirtió en la película más taquillera de la historia del cine argentino, al haber alcanzado 3,5 millones de espectadores sólo en Argentina. Pero siendo Argentina el país latinoamericano que más largometrajes produce, no es sorprendente que su éxito haya traspasado sus fronteras inmediatamente, y que Relatos salvajes se haya beneficiado de "su tradición fílmica de décadas, presente en el imaginario del público latinoamericano" (González 16).

* fconrod@fau.edu 
Con razón, los relatos no parecen tener mucho que los vincula fuera de la pérdida de control total que sugiere el adjetivo salvaje. Pero no se trata precisamente del noble sawvage de Jean-Jacques Rousseau, sino del puro Id freudiano que se vuelve bárbaro, en un país que tanto alaba el psicoanálisis y percibe la existencia con términos derivados de Freud y Lacan. Todos los personajes, de hecho, parecen querer luchar contra una ideología opresora y limitante que parte del Ego. La represión surge en estos relatos de casos ordinarios desde un código de comportamiento social que engendra el conflicto interior entre Id y Ego en los personajes. Todo es un dilema existencial(ista) que deriva de situaciones absurdas e irracionales. En cada uno de estos capítulos desconectados, pero con sentido, los personajes arquetípicos pueden decidir mantenerse en el sistema que controla sus acciones, o rechazar ese sistema con su ideología de control. La decisión ética viene en el momento que se enfrenta el personaje con el dilema emocional dentro de su relato. Aunque cada dilema ideológico es específico y particular, todos mantienen una estructura en común: la del límite al cual llega el personaje central cuando deja de aceptar que lo/la controlen y, en retorno, quiere expresar su primitividad emocional de una forma que va en contra del orden social establecido con sus reglas de comportamiento.

En el primer relato, "Pasternak," un hombre cuya cara nunca se revela decide reunir a todos sus enemigos en un mismo avión que pilota, y decide estrellar el avión contra sus padres que leen tranquilamente al lado de su piscina. En "Las Ratas," una cocinera decide matar salvajemente a un hombre para vengar el trato a la mesera. En "El más fuerte," dos hombres deciden expresar la furia primitiva que sienten por un simple conflicto de conductores. En "Bombita," un hombre, harto de la burocracia automoviliaria, decide poner una bomba en el auto que le van a remolcar. En "La Propuesta," de forma más problemática, se observa un dilema en el cual un padre de la alta burguesía decide pagar a su empleado de clase indígena para que se declare culpable de un crimen que cometió su hijo. Finalmente, en "Hasta que la muerte nos separe," la novia de la boda, en vez de mantener la postura que exige su posición central, cae en un ataque de nervios al enterarse que su nuevo esposo la engañó con una colega de oficina.

Lo crucial es siempre la decisión ética que toman estos personajes, cómo deciden actuar de una forma anormal o socialmente inaceptable. El filósofo esloveno Slavoj Žižek menciona en "Tolerance as an Ideological Category" que "a choice is always a meta-choice, a choice of the modality of the choice itself; it is only the wo- man who does not choose to wear a veil who effectively chooses a choice" (663). Igual que esta mujer hipotética que decide ir en contra de algún código moral por rechazar el velo, los personajes de Relatos salvajes deciden romper con las acciones morales y socialmente aceptables. En esta película vemos arquetipos argentinos decidiendo, rozando en el proceso con la caricatura, luchando en contra de las ideologías de control del pueblo. El problema en vez, se encuentra en la causa, o mejor dicho, el origen de estas ideologías, que da forma social a un problema psicológico personal que exige decisión vital.

Las decisiones éticas que condicionan el comportamiento social esperado suelen basarse en el miedo psicológico a un padre imaginario castigador. En cada relato, se llega al momento del enfrentamiento del personaje con este padre imaginario, el mismo padre que amenaza al individuo con algún castigo. El patrón que se observa, de relato en relato, no solo es la respuesta a la situación crítica en la cual se encuentra el personaje, sino también su decisión de dejar de temer al padre imaginario. En este momento de realización personal, el/la protagonista prefiere satisfacer sus necesidades emocionales y purgar sentimientos reprimidos demasiadas veces en el pasado. Asimismo, lo que la audiencia ve, en estos momentos de decisión, son varios instantes de catarsis extrema para los personajes, que en torno ofrecen un tipo de catarsis indirecto a un público familiarizado con el temor a un padre imaginario. Como lo describe Adrían Ferrero, "la película se vuelve un espejo en cuya especularidad logramos reconocer algunos de nuestros miedos, fantasmas y experiencias temidas" (369). Considerando este miedo social fundamental como condición psicológica central en la película, este artículo propone una aproximación tríptica que permite encajar este concepto de padre imaginario dentro de una complejidad argentina que también involucre el trauma y la neurosis, ambos directamente conectados con la figura paternal que se sale de lo Simbólico para operar dentro de lo Imaginario, el espacio donde se rompen todas las leyes y enseñan su carácter arbitrario en el proceso de destrucción.

\section{Vuelos Traumáticos y la Pista Almodovariana}

España y Argentina tienen experiencias traumáticas parecidas, ergo comportamientos éticos y neuróticos especulares. En este sentido, Damián Szifrón puede estarle agradecido al director español Pedro Almodóvar y a El Deseo, S.A. por producir Relatos salvajes. Es obvio que 
Almodóvar es un aficionado del cine argentino y del humor negro, y su conexión es visible por las varias colaboraciones que ha tenido dirigiendo actores argentinos como Cecilia Roth o Darío Grandinetti. Éste último, de hecho, es el personaje central de "Pasternak", el primer relato. También queda claro que Almodóvar anticipó el éxito de la película al leer el guión y quiso contribuir tanto a nivel económico como ideológico. El español detecta en el proyecto del argentino una terapia de choque medio cómica para un público angustiado, con la paciencia muy limitada, y ya no al borde de un ataque de nervios, sino en pleno ataque. En este sentido Relatos salvajes sigue de cerca los pasos de Los amantes pasajeros (2013), penúltima obra de Almódovar a la fecha: los pasajeros no se encuentran en la cabina por casualidad completa y tienen unas conexiones inesperadas; políticas y sexuales en la película española, cósmicas y orquestadas en la película argentina.

Con unas economías que no parecen despegar nunca, la metáfora del vuelo como reflejo de las sociedades españolas y argentinas cuyos miembros se encuentran encerrados en un mismo espacio, apunta a un miedo que muchos comparten: que el avión, como la sociedad, termine estrellándose, ya sea por culpa del mal tiempo o debido a un error técnico o, como vemos en el primer corto de Relatos salvajes, por un "atentado-suicidio" del piloto. $\bigotimes$ Son los nervios y la poca paciencia que llevan al individuo a buscar una resolución de su trauma en conductas violentas inspiradas por un retorno a su estado salvaje, dejando riendas sueltas al Id freudiano. La ruptura con las reglas sociales de comportamiento es un rechazo total del Orden Simbólico que encarna la figura del padre según el psicoanálisis Lacaniano que una gran parte de la cultura argentina conoce y practica. Se borran las fronteras entonces entre la casualidad y lo concertado para demostrar con ojo pos-moderno que la conducta violenta puede convertirse en un espectáculo hasta cómico, mientras se explicita la conexión entre dicha conducta y el trauma de donde origina. En definitiva, el público de Relatos salvajes se sentirá obligado a burlarse de su propia consumición de psicoanálisis. La intervención inútil del psicólogo de Pasternak que golpea la puerta de la cabina en un último intento de hacer entrar en razón al suicida ilustra la propia ineficacia del argumento Lacaniano a salvar a todo un grupo representativo y emblemático de la sociedad argentina.

Esta situación absurda del corto inicial no es sólo producto de la fantasía de un joven director, sino que también se averigua, se refleja, se observa, y se intuye en una realidad de hiper-mediatización del tráfico aéreo, donde el trauma individual y el colectivo se acaban confundiendo. Dio la gran casualidad que el corto introductorio de Relatos salvajes tuviera resonancia premonitoria del estrello del aparato de Germanwings entre Barcelona y Dusseldorf ocurrido en marzo del 2015, otra pérdida de paciencia y ataque de nervios de un piloto visiblemente incapaz de resolver su condición de traumatizado. En algunos países europeos, como en Inglaterra, la película se estrenó unos días después del evento, lo cual creó polémica ética acerca de $-\mathrm{y}$ hasta publicidad para - la película argentina.

La experiencia traumática del vuelo, su representación en estas dos instancias cinematográficas recientes, tanto como la visión de la responsabilidad humana en los traumas ocasionados que comparten ambas, nos demuestra que solo el enfrentamiento de lo cómico con lo trágico, y viceversa, puede llevar al público a entrar en un proceso terapéutico, aunque no fuese en ningún momento la intención del director tener una sincronización tan evidente con una noticia planetaria. Y bien sabemos que la terapia psicoanalítica es una práctica muy común en Argentina, tanto como bailar el tango o leer las cartas del tarot. Existe una voluntad cultural y hasta nacional de coincidir con la realidad a través de estos modos, dentro de varios más. Como lo dice la maestra de colegio de Pasternak a los demás pasajeros: "Acá hay conexiones cósmicas..." (diálogo, figura 1), rechazando la posibilidad de que sea mera casualidad. En este sentido, la película de Szifrón es un producto artístico que se auto-define con voluntad de curar al público de sus traumas colectivos e individuales, con la misma ironía trágica y aleatoria que puede tener el tango, o las premoniciones del tarot, que hace que la cultura argentina es una de las pocas que sabe reconciliar y unir lo esotérico con lo científico, y ver "conexiones cósmicas" en la vida cotidiana.

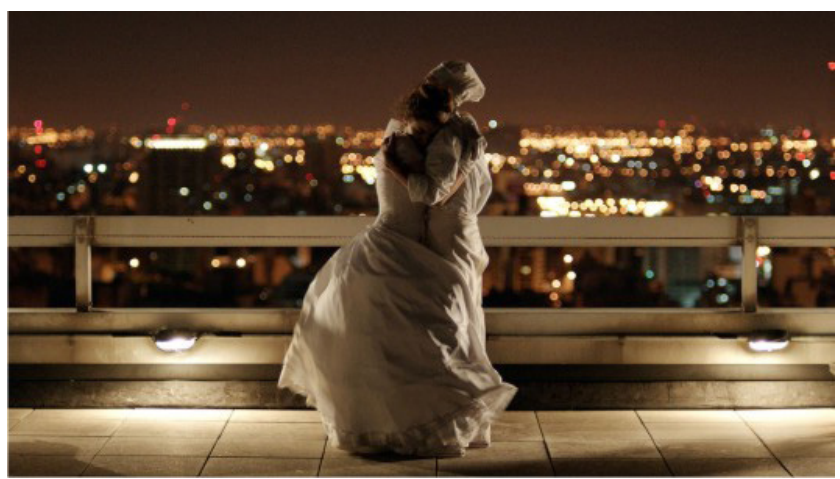

Figura 1 
Tampoco es ninguna casualidad que Pedro Almodóvar siempre haya admirado esta capacidad que tienen los argentinos de convertir lo trágico en cómico, y viceversa, un arte no tan identificable en la cultura española. Recordemos, por ejemplo, el enigmático personaje de Lola en Todo sobre mi madre (1999), un travestí argentino que dejó embarazada a dos mujeres, Manuela y Rosa, una argentina y otra española, que se acaban juntando por compartir experiencias traumáticas semejantes. Sí, en este sentido, Almodóvar parece acercarse a una nueva fuente de inspiración con la producción de Relatos salvajes, pero en terreno conocido. Una vez más, la carrera de productor de Almodóvar se destaca por su atracción al cine que incomoda y que violenta, desde el romanticismo lunático de My life without me, el mundo de fantasía de Guillermo del Toro o la de Cobrador (In God We Trust). Sin embargo, cabe destacar también que el tema de la pérdida de control ético presente en Relatos salvajes cruza la obra entera de Pedro Almodóvar, desde Mujeres al borde de un ataque de nervios, pasando por Átame, Tacones Lejanos, Carne Trémula y, sobre todo, La mala educación, película en la cual ya se proyecta de forma meta-cinematográfica la histeria de Los amantes pasajeros. Le fascina la histeria individual que se condiciona en la colectiva: en este aspecto, Argentina y España tienen mucho que aportarse en el proceso terapéutico que requiere el trauma causado por años de dictaduras respectivas. Ambas tuvieron que tener, en este sentido, mucha paciencia en su sanación ética.

El formato de la película argentina es a la vez tradicional e innovador. El corto introductorio de Relatos salvajes dura apenas siete minutos, pero afina todos los instrumentos cómicos que se van a usar luego en la película. Sin embargo, en el corto de Damián Szifrón, el director de la película, el tema de la venganza va muy orientado a los actores de la vida de uno, que pusieron obstáculos $\mathrm{y}$ frustraciones, que acabaron juntándose para mantener una condición traumática. El piloto, cuya cara no se ve en el corto, es un músico frustrado que acaba juntando de forma sinfónica a todos los que originaron el rechazo, el trauma y el bloqueo desde su niñez, incluyendo al inútil psicólogo que no fue capaz de curarlo. Sabemos muy bien lo que los músicos frustrados que no entran en los conservatorios son capaces de hacer: Adolf Hitler es el ejemplo más claro que nos ha dejado la historia. Al ser rechazado del conservatorio de Viena, se metió directamente al ejército y la política. Tal vez sea que Szifrón parta del caso del Fürher para construir su argumento con el caso ficticio de Gabriel Pasternak, mezcla de ar- cángel y de inmigración rusa a la Argentina. El nombre de Pasternak también está asociado, obviamente, a Boris Pasternak, el premio nobel de literatura ruso autor del Doctor Zhivago, que comparte con Hitler el haber sido rechazado de la academia de música (en su caso la de Moscú), y coleccionó frustraciones a lo largo de su vida, entre otras amorosas. Es interesante notar también que Boris Pasternak murió en un accidente de avión mientras mantenía una relación con una mujer uruguaya.

Como se puede constatar rápidamente en el corto, no sólo reunió el piloto Pasternak a todas las personas que le pusieron obstáculos y que hicieron que su situación traumática inicial fuera en crescendo, sino que también les puso en orden cronológico dentro de la cabina de pasajeros: el compañero de clase que le pegaba en el colegio, la profesora que le hizo repetir el curso, están por delante. La ex novia modelo y el profesor de música que inician la conversación y que provocan la toma de conciencia que este viaje no es un concurso de casualidad, están sentados en el centro de la cabina que representa el primer gran doble fracaso de la vida de adulto de Pasternak. La otra mitad del avión está llena de personajes que siguieron alimentando la neurosis y la depresión de la "pobre criatura" Gabriel Pasternak que termina cometiendo un acto de auto-terrorismo. Al igual que Los amantes pasajeros de Pedro Almodóvar, este corto de Relatos salvajes ordena a los pasajeros según una metáfora que refleja la cronología neurótica.

Como lo señala Slavoj Žižek en el 2012 en su documental The Pervert's Guide to Ideology y en un libro titulado Living the End Times, este género de cine viene, en la realidad capitalista, a revelar antagonismos escondidos o contenidos, o bien destapando una ideología opresora, o bien denunciando un falso mensaje de universalidad. El filósofo esloveno subraya al respecto que

"[ $\mathrm{t}$ ]he standard complaint about how global capitalism corrodes and destroys particular lifeworlds should be countered by the claim that such lifeworlds are invariably based on some form of domination and oppression, that to a greater or lesser extent they conceal hidden antagonisms, and that any emerging emancipatory universality therein is the universality of those who have no 'proper place' within their particular world, a universality that forms the lateral link between the excluded in each lifeworld" (Living 286)

El capitalismo, siendo además un sistema obsesionado con la prevención, no resulta extraño entonces que las ideologías que se van reflejando en el séptimo arte contengan e inyecten una dosis de choque preventivo que se base en protagonizar personajes 'que no tienen su propio 
lugar'. Entramos entonces en la era de la terapia de choque, donde el cine ofrece sus premoniciones sobre eventos que se irán confirmando en la realidad. Siguiendo los pasos de Žižek y llevándolos a la esfera del cine argentino, Joanna Page añade que es necesario concebir "the role of Argentine cinema within the national imaginary, in an era in which culture and politics are becoming increasingly difficult to distinguish" (7). La representación cómica del vuelo no sólo sirve de terapia de choque sino también de crítica del sistema capitalista que, al igual que el Pasternak de Relatos salvajes, orquestra su propio suicidio, llevándose a la vez a una muestra de la sociedad por marcar la culpabilidad y complicidad de todos los actores que componen este aparato ideológico.

Asimismo, tanto Los amantes pasajeros de Almodóvar como Relatos salvajes son muestras culturales de un humor que tiende a seguir despegando en las culturas hispanas de la última década, para apartarse a la vez del humor global concebido y promocionado por EEUU y Hollywood. Prefieren buscar una vuelta al origen primitivo y presentar una dimensión psicoanalítica intracultural sobre la cuestión del trauma y de su resolución. El poco éxito o las controversias que se identifican a la recepción de estos productos cinematográficos en los países anglo-sajones subrayan también que la terapia de choque ya no se percibe como fenómeno global. Sin embargo, Adrían Ferrero avanza en la idea de que Szifrón logra internacionalizar la psicología argentina con Relatos salvajes (370). A la vez, tanto Almodóvar como Szifrón tienen en común su pertenencia a unas generaciones que tuvieron que desarrollarse en una realidad pos-dictatorial en la cual fueron víctimas del trauma creado por unas figuras paternales, al crecer en la represión dictada por un Orden Simbólico revocado. No nos parecerá nada extraño, por lo tanto, que el avión de Pasternak se estrelle sobre su propio padre, la causa y el origen del proceso traumático, y que el atentado combinado con suicidio sea a la vez un parricidio.

En este sentido, el corte inicial de la película argentina ofrece la llave de ambas películas, y tal vez del origen mismo del trauma hispano dentro de una perspectiva global: el estar encerrado en una cabina y enfrentado a una constante tensión entre el condicionamiento cultural (y paternal) y las frustraciones que salieron de querer escapar de ello, seguido por la imposibilidad de hacerlo. El parricidio es su única salida. ¿Y a quién le va a asustar matar al padre en un país donde el padre ha matado a tantos de sus hijos?

\section{El Padre Imaginario y la Vuelta a lo Salvaje del Id}

El Padre Imaginario es, según Lacan, el padre de la prohibición que genera la neurosis social. A su alrededor, el sujeto construye sus fantasías que van convirtiéndose en leyes de sociedad. Es responsable por la represión y la frustración que nos pueden conducir a comportamientos extremos que equivalen a un parricidio simbólico. Dentro del contexto argentino, "no solo es el retorno de lo reprimido del trauma del asesinato del primer padre en lo inconsciente colectivo, sino que además es el evento que posibilita el nacimiento de una nueva cultura" (Sorbille 25).

Al final de "Pasternak" el avión se estrella sobre el padre, y empiezan a desfilar inmediatamente los créditos de apertura donde se yuxtaponen fotos de animales con nombres de actores, todos muestras significativas de esa nueva cultura. Junto al nombre Julieta Zylberberg, la actriz que interpreta el papel de la moza en el siguiente cortometraje titulado "Las Ratas", vemos la imagen de un cordero. Ya en estos créditos se caracteriza de forma inconsciente a la moza como personaje inocente que tendrá que ser sacrificada por la redención social de los demás. El mismo proceso ocurre con Rita Cortese, quien interpreta el papel de la cocinera, y a quien se le vincula con un gorila, mezcla salvaje de lo agresivo con lo protector. Estas imágenes subliminales y animalísticas ofrecen un marco de un personaje joven e inocente apoyado por un personaje protector femenino pero paternal, y potencialmente agresivo.

No es extraño por lo tanto que empiece la secuencia con una vista de falacia patética, durante una agresiva tormenta, con un plano picado que proyecta más de la mitad de las letras de un cartel que dice "RESTAURANTE”, indicando un rutero típico, lugar de refugio y de protección. Se han apagado las luces, y aunque claramente está abierto el restaurante, parece casi abandonado. Las otras luces del lugar no hacen más que aludir a la posibilidad de gente adentro, ya hecho que no cierra el negocio, y la falta de autos o de cualquier movimiento humano o social solo aumenta este sentido de exterioridad y aislamiento. Está claro que este restaurante no se encuentra en pleno Buenos Aires, ni en otro centro urbano, sino más bien en una arteria de circulación interurbana. Como para reforzar la idea de no estar en la ciudad, entra una camioneta, vehículo estereotípicamente asociado con el mundo rural.

Continuando con las caracterizaciones y contextualizaciones del cortometraje, aparece una moza y el único 
cliente del restaurante, cuyas primeras palabras insultan en forma de broma a la moza. La forma de vestir del hombre, que pronto se conocerá bajo el nombre de Cuenca, es típica del contexto rural. Se quita su chaqueta para revelar una camiseta de botones con mangas largas, un chaleco, y un pañuelo de estilo gaucho. Sólo le falta el simbólico gorro para completar su asociación con la Argentina del exterior. En este sentido, este personaje toma el relevo del arquetipo de la masculinidad rural y salvaje que se observará en el capítulo posterior.

Cuenca es un mafioso que, por rematar la casa de la moza y su familia, llevó al padre de la moza al suicidio antes de acosar a la madre, reflejando el proceso del padre imaginario lacaniano. Desde que su madre y ella tuvieron que huir del pueblo, la joven le tiene a Cuenca un rencor descontrolado que comunica a su compañera: “¿Sabés cuántas veces soñé con tenerlo así, delante de mí? Yo algo le voy a decir" (diálogo, figura 2). En un principio, su necesidad dictada por el Ego es de comunicarle su sufrimiento para resolver su trauma, y no de vengarse. La moza es de la generación siguiente a la de la cocinera y la de Cuenca, lo cual destaca que era inocente cuando toda la Argentina vivió un periodo extremadamente violento. En contraste, ella creció en una sociedad que enfatizó la necesidad de resolver las tensiones con el diálogo constructivo basado en la psicología de masas consumida en el país para resolver los traumas nacionales e individuales.

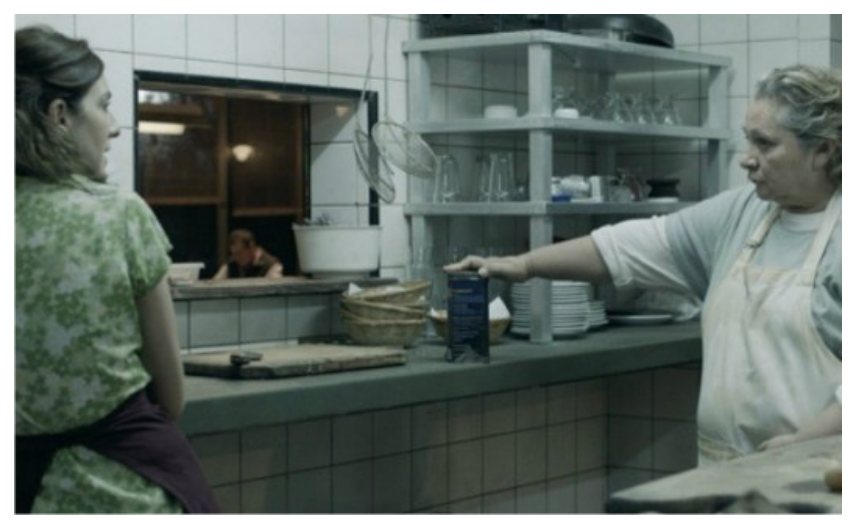

Figura 2

La cocinera-gorila adopta al revés un discurso más violento. Le responde a la moza: “¿Por culpa de ese tipo se suicidó tu papá y lo único que se te ocurre es insultarlo? ¿Por qué no le ponemos veneno para ratas en la comida?” (diálogo, figura 2). Estas palabras se escuchan sin que se vea a la cocinera directamente, como si fuera voz de consciencia. Se asombra la moza, y la cámara gira hacia la cocinera que pronunció esta sentencia de muerte. Se divide claramente el espacio del restaurante en esta toma, simbolizando el dilema psíquico de la moza. El comedor del restaurante, donde la moza se enfrenta con Cuenca, representa claramente su ego. La cocina representa en torno su Id y ganas de venganza violenta, contra el cual intenta luchar. Como en un cuento arquetípico, la moza se identifica con el cordero inocente, Cuenca con el granjero malo que rompe la armonía al llevar la familia al matadero, y la cocinera con la bruja que sugiere un restablecimiento de la armonía a través de la violencia, según lo dicta el Id. Cuenca no solo es un mafioso que afectó la vida de esta chica, sino que también es una persona poderosa cuya influencia es más peligrosa que sus acciones. La misma cocinera sugiere que vale la pena matar al hijo de Cuenca también, porque "va a crecer. Tal palo tal astilla" (diálogo). Los abusos de parte del padre se pueden continuar por parte del hijo, quien corre el riesgo en torno de reproducir el patrón del padre imaginario.

Se complica aún más cuando la cocinera envenena el plato de comida, es decir, cuando el Id actúa de tal forma que el Ego se queda inconsciente de la acción del Id. El Ego le comanda que no debería envenenar por miedo de ir a la cárcel, una amenazante herramienta de control. El Ego no puede ni quiere rebelarse en contra del padre real que representa Cuenca, por miedo al castigo del padre imaginario, un castigo que se manifiesta a través de la policía. En torno, al Id no le importa la cárcel, y hasta habla de la cárcel como un lugar que no es tan malo, ya que se recibe comida gratuita y no hay que pagar alquiler. La cocinera ve que el posible castigo es menor que el beneficio del acto violento rebelde. Žižek busca entender "la oposición a toda forma de violencia" (algo que demuestra la moza), y presenta unas preguntas importantes:

¿No hay algo sospechoso, sin duda sintomático, en este enfoque único centrado en la violencia subjetiva (la violencia de los agentes sociales, de los individuos malvados, de los aparatos disciplinados de represión o de las multitudes fanáticas)? ¿No es un intento a la desesperada de distraer nuestra atención del auténtico problema, tapando otras formas de violencia y, por tanto, participando activamente en ellas? (Sobre la violencia 21).

Mientras la moza se enfoca en lo específico de los actos de Cuenca y el acto de la cocinera, la cocinera ve el peligro en macro, y la verdadera amenaza de un mundo que no castigó a Cuenca, cuyas acciones llevaron a su padre a cometer suicidio.

El fin del cortometraje, contiene mucho simbolismo psico-social. La moza, tratando de convencer a Cuenca que no coma más, le retira las papas fritas, a lo cual 
él responde con furia y violencia, hasta que salga la cocinera a defender a la moza y matarlo. A nivel alegórico, en vez, vemos el Ego que, con una pequeña agresión, busca ayudar al poder hegemónico y su ideología, los cuales reaccionan de forma castigadora por la agresión del Ego sujeto, y en fin, sale una defensa del Id en un momento de pura violencia. Es una rebeldía forzada por la crueldad del grupo poderoso. En fin, el Ego no tiene ninguna culpa, y llevan a la cárcel el Id, quien todavía tiene que ser castigado, pero posiblemente ha liberado el Ego de la ética dictada por la hegemonía opresora.

Quizás el capítulo más gráfico de la película de Szifrón sea "El más fuerte", donde vemos una pelea a muerte de dos conductores que representan los extremos de la sociedad argentina. Siguiendo con el hilo que parece reunir los relatos por el tema de la venganza, se abre esta parte con una parodia de anuncio de coche: Leonardo Sbaraglia interpreta un hombre de negocios conduciendo un Audi de última generación, como fondo música de piano enfatizando el carácter pequeño burgués del personaje. Lanzado por una carretera desierta de la provincia de Salta, esta apertura reproduce toda la dinámica de marketing del automóvil y se centra en la potencia del vehículo, potencia en la cual se refleja su conductor al considerarla extensión de su propia potencia masculina. Como lo señala en Sobre la violencia (2009) al hablar de estas percepciones equivocadas: "La experiencia que tenemos de nuestras vidas desde nuestro interior, la historia que nos narramos acerca de nosotros mismos para poder dar cuenta de lo que hacemos, es fundamentalmente una mentira. La verdad está fuera, en lo que hacemos" (64). El personaje genérico y sin nombre que encarna Leonardo Sbaraglia narra una historia en la cual se percibe como hombre varonil y fuerte, hasta que su verdad aparezca de forma brutal en su enfrentamiento con un conductor de zona rural, con automóvil usado y típico de la vida del interior argentino, donde el vehículo no es símbolo de fuerza.

El círculo de violencia empieza por una diferencia de velocidad y la voluntad del burgués de doblar el vehículo lento del hombre rural. En el primer enfrentamiento con el campesino, el hombre urbano se permite responder a su oponente con insultos propios del argentino que disminuyen la virilidad del pseudo-gaucho, y lo acompaña de un dedo mayor (Figura 3) que también evoca la potencia sexual superior del conductor, una violencia verbal y gestual típica de los episodios de road rage (conducta agresiva de conductores).

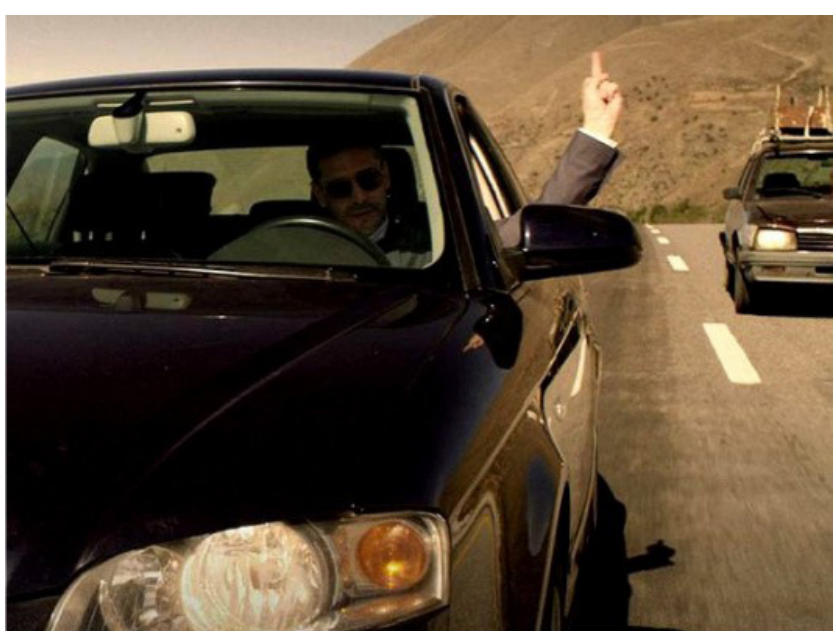

Figura 3

Unos cuantos kilómetros más adelante, se da cuenta de que "se [l]e pinchó una goma” (diálogo) del Audi nuevo, el hombre urbano demuestra su completa incapacidad de cambiar la rueda, prefiriendo llamar al servicio de remolque por su teléfono celular de última generación. Fuera del coche, sin embargo, es impotente en pleno paisaje natural y desértico. Lo cual no es el caso del campesino que lo alcanza a pesar de desplazarse lentamente, confirmando la sabiduría universal de la fábula de La Fontaine, La liebre y la tortuga. Los dos extremos de la sociedad argentina no tienen otro remedio que chocar en una pelea sangrienta que, partiendo de un acontecimiento sin importancia, les llevará a ambos hasta una muerte que convierte a la oposición binaria que simbolizan en un irónico retrato de amor absurdo, y percibido como crimen pasional por la policía que llega a la escena demasiado tarde para parar la violencia.

La presencia implícita del Padre Imaginario se revela en la lucha de los dos antagonistas: el porteño quiere afirmar su virilidad limitada a la posesión, y amenazada por la fuerza física del hombre rural que defeca y orina sobre el Audi en cuanto su enemigo urbano se encierra en el coche. La humillación castradora es extrema, puesto que este comportamiento se revela pre-simbólico, es decir, antes de la entrada en las reglas sociales impuestas por el Padre. La reacción del burgués (y probablemente del público que se identificará más con él y de paso con el Orden Simbólico que se impone en estas situaciones) es una mezcla de miedo y disgusto profundo. A la vez, el comportamiento del hombre bruto, obrero y proletario al exterior del coche subraya una profunda castración del capitalista encerrado, sugiriendo que él también "se está cagando" pero, en su caso, de miedo. Cuando consigue arrancar el coche y recupera su potencia de movimiento 
y su fuerza mecánica, decide dar vuelta a la escena del conflicto en vez de huir, precisamente porque ya no sabe responder a este Padre Imaginario que se encarnó en la figura de un campesino castigador. Nota subrayar que este tipo de humillación del hombre burgués porteño por otro rural mucho más viril es un leitmotiv del cine argentino de los últimos años que culmina en la película de Mariano Cohn y Gastón Duprat, El hombre de al lado, estrenada en el 2009.

El hybris de violencia coge un aspecto más individual en "Bombita", el siguiente capítulo en el cual actúa otra estrella del cine argentino, Ricardo Darín. En algún puesto oscuro, se escucha un taladro, hasta ver un pequeño círculo de luz que muestra una linterna sobre un casco, y después una nariz y una mejilla que sugieren una cara, sin revelar la identidad de la persona con el casco. La cabeza desaparece, nos lanza en esa oscuridad completa de nuevo, sube de nuevo, y llena el agujero con un palo de dinamita, y de vuelta la mirada del espectador se encuentra en una oscuridad completa. La escena cambia y vemos el cuerpo del personaje quien puso la dinamita, pero todavía no vemos la cara que nos permite reconocerlo. El personaje está en un chiaroscuro sutil, su cuerpo envuelto en otra oscuridad completa, pero su linterna ilumina sus manos que conectan una mecha a la dinamita. El scuro de este chiaroscuro es opresor sin las dos columnas o paredes que sirven como marcos dentro de la escena, pero no elimina la posibilidad de un oscuro sin fin. Los marcos ofrecen una espacialidad cómoda, y unos límites comprensibles para una oscuridad que no tiene ni matices ni sombras, y en eso, no tiene espacio. Es Borges quien, en su cuento "La biblioteca de Babel," juega con el posible o falso infinito que surge de un número indefinido, y en esta oscuridad indefinida, sin contexto o pistas, experimentamos momentáneamente un falso infinito con momentos de luz que dan la esperanza de liberación de la oscuridad. En fin, nos enteramos que el casco, la nariz, y las manos pertenecen a Simón, quien tira una palanca y enciende unas luces estroboscópicas mientras la cámara se va por el túnel, alejándose de Simón, aún envuelto en la oscuridad.

De esta oscuridad opresiva, se sale a la luz del día, donde Simón (Ricardo Darín) se quita su casco, antes de detonar la dinamita que ha puesto. Vemos las detonaciones en la base de la estructura, pequeñas luces que surgen de espacios oscuros, y la estructura se derrumba en una secuencia organizada de izquierda a derecha. Simón, ingeniero de explosivos, con cálculos precisos, usa explosiones controladas para tirar abajo un pedazo de infraestructura que hace minutos lo tenía envuelto en una oscuridad que parecía, fílmicamente, inescapable. Y sus compañeros lo aplauden y lo felicitan por su trabajo bien hecho. La primera secuencia de "Bombita," el cuarto cortometraje de Relatos salvajes, abre con dos detalles claves que luego se verán en la última secuencia: Simón detona una bomba, y sus compañeros lo aplauden.

Después de esta escena llegamos al punto inicial de la trama, cuando le remolcan el auto a Simón. La trama se desarrolla a través el deseo de Simón en reclamar por la observada injusticia de recibir una multa por su auto mal estacionado cuando el cordón no estaba suficientemente pintado para denotar que no se debería estacionar allí. Simón llega al VTA y sin poder terminar de explicar su situación, es interrumpido por el encargado quien le pide su cédula. En esa pequeña interrupción ya se observa la primera negación del gobierno hacia Simón: su explicación no tiene la misma importancia que tiene el documento que declara su identidad oficial. Simón le responde al encargado "Si podés, hablame bien," que sirve como recordatorio de la humanidad de Simón que debe ser respetado, al cual se le ofrece otra negación con "Le estoy hablando bien, señor" (dialogo). Sigue un breve intercambio que termina con Simón quien les demanda que le arreglen el asunto y que le pidan disculpas. El encargado se ríe, Simón le asegura que le está hablando en serio, y eventualmente el encargado le explica que no necesita más prueba que el acta del oficial. Hasta este punto, dos veces el encargado le ha puesto mayor importancia a un documento que a Simón: su identificación importa solo con la cédula, y su testimonio es superado por el acta.

Aunque no es ninguna situación extraña, sino que es una situación completamente cotidiana, esta experiencia con el intento de reclamar una multa injusta señala un problema grave de la relación entre el sujeto social y la burocracia. La burocracia, asumiendo en esta escena el papel del padre imaginario, se utiliza de forma controladora envolviendo a Simón en sistemas de leyes y códigos que él no puede superar con solo hablar. Aunque el protagonista habla con un hombre, ese hombre tiene la autoridad del gobierno detrás de él y tiene licencia en resolver el conflicto con declaración en vez de litigio, una situación que deja a Simón completamente fuera de control. Luego, llega tarde al cumpleaños de su hija por culpa del tránsito, otra situación fuera de su control. Cuando luego le pregunta su esposa porque no dejó el auto para ir a buscarlo otro día, él le responde: "Yo estoy harto de que me roben la plata” (diálogo). El problema 
de Simón es la frustración de ser dominado constantemente por un sistema que él no puede cambiar.

Eventualmente Simón sí encuentra un apoyo cuando va a reclamar la multa de nuevo, con un nuevo encargado, y al decirle a ese nuevo encargado que es un chorro (ladrón), la gente en la cola empieza a aplaudir. Con ese apoyo detrás, Simón agarra un matafuegos y rompe el vidrio que lo separa del encargado. No logra romperlo totalmente, pero sí se ve que este vidrio, que separa literalmente los dos hombres, y metafóricamente el mundo del gobierno con ese del individuo, se deja con grandes grietas. La violencia de Simón logra establecer algún respeto (o temor) desde el lado gubernamental. Cuando se encuentra en la misma situación de antes, con su auto remolcado por segunda vez, decide cambiar algo.

En la violencia, Simón es reconocido por el encargado, la persona que representa el gobierno en este conflicto. Slavoj Žižek, describió en su conferencia de la European Graduate School titulada "A plea for ethical violence," [1] el proceso del sujeto quien se entiende a través del encuentro con otro sujeto, una situación en la cual se encuentra Simón. El problema es que él quiere ser visto y reconocido de una forma en particular, que requiere respeto e igualdad, que se le niega por parte de la autoridad del gobierno. Su identidad se forma a través de una cédula y un acta. En fin el decide detonar una bomba en el VTA, y con ese acto termina siendo reconocido por el gobierno. Se le da un nuevo nombre, "Bombita", asumiendo un poder imaginario para resistir a la burocracia del gobierno. Mientras el resto de la población se mantiene callado y bajo el control de comportamiento del opresor gubernamental y social (padre imaginario y denominador común de toda una sociedad), Simón decide pasarse de ese límite. Aunque parezca que ningún otro lo hubiese hecho, muchos más querían ver pasar lo que pasó. Incluso, justo antes de la detonación, una mujer en la misma posición que tuvo Simón al inicio del cortometraje, hablando con el mismo primer encargado, declara: "Hasta que no pase una tragedia, no van a parar ustedes" (diálogo). Pasa una serie de twitts que hablan del hecho de Bombita (Simón), del efecto que tuvo su detonación, y el apoyo social que recibe, con dos ejemplos específicos teniendo más importancia: "Cuestionan la legitimidad del contrato con la empresa que opera las grúas" y "En las redes sociales, miles de usuarios piden la liberación del ingeniero 'Bombita'."

En la última escena la hija de Simón y su ex esposa van a visitar a Bombita en la cárcel, con una torta de cumpleaños, mientras los otros presos le felicitan con una canción. Cierra el cortometraje con enorme aplauso de parte de los presos, un público que apoya las acciones de su nuevo héroe, él que se enfrentó contra la burocracia que quiso controlarlo. Con esta última escena, admiramos cómo la sociedad perfecta se ha reconstituido a través de la rebeldía contra el padre imaginario. Los verdaderos prisioneros son, pues, los que siguen viviendo en el mundo exterior, y que siguen presos de la neurosis engendrada por esta figura. Dentro de estos presos que se ignoran, los más afectados son los que mantienen la hegemonía y vigilan la estabilidad de la ética que se necesita para mantener el orden social sin cambiar. No resultará extraño, entonces, que los dos últimos capítulos de Relatos salvajes sean dedicados a explorar las cárceles psicológicas de la alta burguesía argentina.

\section{La Burguesía Neurótica Argentina}

En los pasos de la mentalidad ilustrada francesa, la sociedad argentina es muy crítica de si misma, hasta en su auto-burla de la clase burguesa. Se sabe desde Molière que esta clase central del sistema capitalista tiene unas complejidades y unos complejos que invitan a la sátira. El ego argentino, en adición, tiene reputación mundial de ser desmesurado. La auto-burla es un instrumento que permite reconocer el Ego y, hasta cierto punto, limitar los desbordamientos neuróticos que pueda ocasionar. Szifrón hace de las tensiones entre clases sociales un leit motiv desde el primer capítulo de la película, y lo enfatiza en "El más fuerte", el segundo corto ya analizado, cuando la alta burguesía y la clase campesina se pelean a muerte. Pero como no es suficiente, lo lleva a un nivel más complejo aún en el cuarto capítulo, "La propuesta".

Este capítulo supera todas las metas del bumour noir, dado la gravedad del tema. Un "hijo de papa" burgués vuelve a casa llorando, despertando a sus padres, como un niño que se ha hecho en la cama. De vuelta del centro a la periferia protegida de la alta sociedad porteña, y bajo la influencia del alcohol, atropelló a una madre con su hijo pequeño, y prefirió huir. En "La propuesta" se expone otro tipo de violencia neurótica, la que genera la diferencia económica. Crespo-Vila y Piñeiro-Naval señalan que "Lo más curioso, sin embargo, es que, por conocida y común, esta situación es, frente a las cinco restantes, la menos epatante para el espectador contemporáneo" (569). Tal vez hay que reconocer que de todos los relatos, es él que menos movimiento tiene. Estos veintiún minutos de pura vergüenza y de tensión psicológica rompen aquí con 
los capítulos anteriores. El director subraya aquí el carácter esencialmente lento del interior burgués argentino. En este sentido, Szifrón retoma otra vez el estilo de Mariano Cohn y Gastón Duprat en El hombre de al lado (2009), una mirada tensa hacia la cobardía de la clase alta y su necesidad irresponsable de sacrificar las clases inferiores para mantenerse en su estatus de privilegio.

Por supuesto, Szifrón no es el primero en hacer esta conexión socio-psicológica. Marx, Freud, Lacan, Deleuze, Foucault, (entre muchos) ya teorizaron todos a su manera filosófica la tendencia neurótica de la clase alta. Luis Buñuel fue uno de los primeros cineastas vanguardistas en explorar esta dinámica con Le charme discret de la bourgeoisie (1972). Cabe destacar que en este capítulo de Relatos salvajes, el representante de la clase, y epicentro de la acción, es el padre, Mauricio. El nivel de neurosis en Santiago, el hijo culpable, es tan alto que no es capaz de asumir la responsabilidad, aunque lo desee hacer en dos ocasiones. El crimen cometido desata la verdadera naturaleza de la relación entre el padre y el hijo en la cual se observa que el control paternal es el origen de la condición neurótica del hijo. Para salvar su reputación y su condición, propone a José, su jardinero, de llevar la culpa del hijo a cambio de 500.000 dólares, porque, según Mauricio, Santiago "no podría sobrevivir en la cárcel" (diálogo). José, sin embargo, siendo de clase baja tiene una condición asumida para poder sobrevivir en este entorno desconocido de la burguesía.

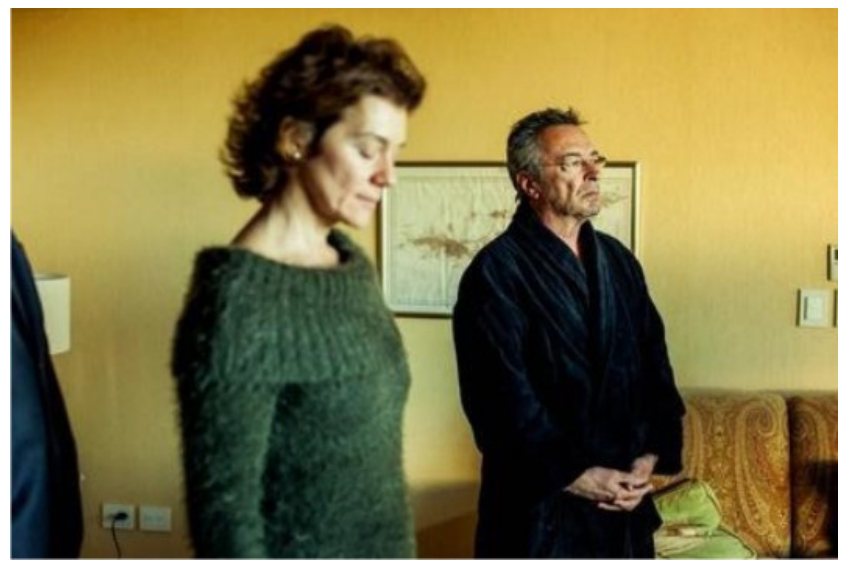

Figura 4

"Lo que te estoy proponiendo me avergüenza... mucho..." (diálogo) empieza diciendo Mauricio a José. Con esta frase que reitera una obligación de la clase obrera de sacrificarse para mantener la hegemonía burguesa, empiezan las negociaciones que van a involucrar al abogado de Mauricio, al jardinero transformado en culpable, y al fiscal que detecta rápidamente la mentira y quiere su comisión. Todos quieren sacarle más provecho a la situación trágica hasta que Mauricio, el padre burgués y detentor del capital, decida cortar los tratos. Se replantea entonces una nueva negociación. El capítulo brilla por sus silencios, sus close-ups y sus miradas cruzadas más que por el contenido de sus diálogos (Figura 4). La violencia salvaje llega al final en los últimos segundos del corto cuando el marido de la víctima mata a José a martillazos. Este momento brutal concluye una anécdota que confirma la supervivencia del orden burgués. Con el único sospechoso muerto, Mauricio estará en condición de conservar su capital casi intacto. Pero muy seguramente a cambio de una alta factura emocional y daños psicológicos que aumentarán la neurosis de cada miembro de esta familia, aunque Szifrón decida no revelar este trágico retrato más allá del golpe final.

$\mathrm{Y}$ es precisamente con la artificialidad de las familias y su violencia subyacente que Szifrón decide seguir y concluir su obra. El último capítulo, "Hasta que la muerte nos separe", es el más largo de la película con diferencia, con casi treinta minutos de metraje. También es el que más parece recordar el público, y eso se debe a su carácter cómico generado por Romina, el personaje central y novia que pierde el control al enterarse en la cena de su boda que su marido tiene una amante y que, por encima, ésta se encuentra dentro de los invitados. Entran los novios en el salón de forma espectacular y ensayada con la música tecno Titanium de David Guetta, señalando la nueva generación y cultura a la cual pertenecen. Pero de repente se interrumpe este tema musical para dar paso a una música tradicional que se toca en las bodas judías. Szifrón entra entonces en un territorio que le es particularmente familiar, siendo él mismo un nuevo ícono del judaísmo argentino. Y como ya lo demostró Woody Allen, no hay directores de cine más críticos del judaísmo que los propios judíos. Esta mirada íntima hacia la comunidad judía argentina introduce otro nivel de violencia neurótica en la película, puesto que la diáspora al Cono Sur es resultado de la persecución nazi en los años 1930 en Europa. Desde entonces, la comunidad en diáspora ha querido mantener su identidad a todo precio, hasta en las alianzas conyugales. Es obvio por el diaporama inicial de fotos que el matrimonio de Romina y Ariel ha sido programado por los padres desde la infancia, y que la celebración tiene mucho más que ver con la unión de dos familias judías y de sus capitales culturales que de dos personas que se quieren.

Sin embargo, cae esta fachada cuando Romina se entera de la relación sexual que ha tenido Ariel con su com- 
pañera de trabajo Lourdes. El choque de Romina es triple de una triple violencia neurótica: 1) la de su argentinidad, que tiene en común con los otros personajes de la película, 2) la que proviene de la opresión de la comunidad judía en Europa y hasta en Argentina (culminando con el atentado de la AMIA en 1994), y 3) la de su condición de mujer engañada por un hombre que le ha sido impuesto de forma implícita. Su instinto la conduce a la azotea del hotel donde contempla el vacío como alguien que está a punto de suicidarse. Pero un cocinero fumando que adopta el papel de ángel de la guardia salvador un arquetipo visto en muchas historias cuando un personaje está a punto de saltar al vacío - la consola y le da razones para seguir adelante (Figura 5). Al escucharle, Romina se queda fascinada por este hombre de clase baja y, después de tomar una profunda respiración, le da un beso que va a derivar en acto sexual improvisado en la misma azotea.

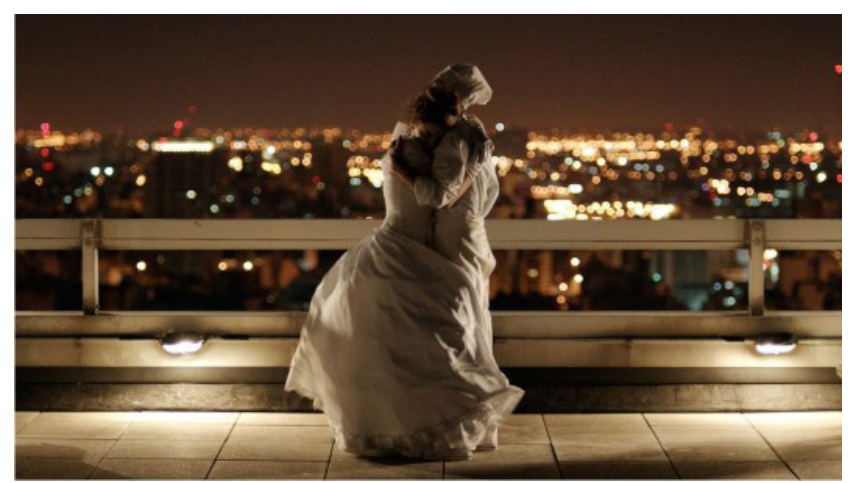

Figura 5

La conexión sexual entre la "princesa judía" y el obrero sabio hace que Romina vaya a dar un cambio de actitud radical frente a la situación crítica en la cual se encuentra. En este intercambio se observa en términos freudianos, y una vez más, como la clase baja está más conectada con el Id mientras la burguesía prefiere una conexión hegemónica con el Ego. En este sentido, la novia se deja despeinar del todo por el cocinero. Cuando Ariel finalmente llega a la azotea y les descubre en pleno acto sexual, Romina le suelta un monólogo ${ }^{2}$-ahora famoso dentro de los aficionados de la película- que le provoca a su marido una reacción estomacal seguido de una vomitona nerviosa como única respuesta. Romina le clava a Ariel un puñal hecho de Id que va a operar disfrazado de Ego para el resto de la sociedad que ambos representan. Lo que sigue cuando la novia vuelve a sus invitados abandonados es una histeria colectiva donde Romina opera una venganza que va más allá del engaño relacional sufrido. Es ahora su comunidad entera lo que quiere desestabilizar, empezando con la amante de Ariel y siguiendo con su nueva suegra. Castigar a Ariel no es suficiente dado que la lucha neurótica de Romina se ha convertido en una de clases sociales en la cual ella asume ahora la posición de clase baja en revolución.

El capítulo se concluye de la forma más inesperada: Damián Szifrón cierra su obra con un final feliz. Tras un caída histérica de los actores principales del casamiento, el orden se re-establece cuando el propio Ariel llega a tener la misma iluminación anti-hegemónica que la que conoce Romina en la mágica azotea. Es desde lo más profundo de su choque emocional que el hijo llorando/muerto en los brazos de su madre, reproduciendo una escena de piedad cristiana al bajar el cuerpo de Cristo en los brazos de la Virgen, se sacude y aparta las manos maternales de su pecho para levantarse y adoptar una actitud de rebelión contra el Ego burgués de donde proviene. En este caso cultural particular, la madre judía asume la función del padre imaginario generador de represión y frustración. Ariel se aleja pues de su madre y se acerca a Romina con este nuevo rostro marcado por su animalidad, y le pide con los brazos abiertos que reconozca en él un hombre que finalmente ha dejado el llanto en el seno de su madre para asumir su Id y, por lo tanto, un verdadero deseo sexual hacia Romina, deseo que contempla la madre abandonada con espanto. Con este gesto, los dos se olvidan de la audiencia y se enlazan sexualmente de la forma más animal que nunca conocieron en su relación. Se realiza entonces la verdadera unión, la que parte de la parte salvaje de ser cuando ya ha reconocido la manipulación del padre imaginario, de la comunidad, de la sociedad y de la condición genérica.

\section{Conclusión}

A pesar de ser un producto comercial de gran éxito con figuras reconocidas del cine argentino, Relatos salvajes consigue dar en el clavo dónde más le duele a la sociedad argentina: en su naturaleza neurótica. La auto-burla sirve de auto-terapia en un contexto donde los personajes centrales chocan con su condición socio-cultural y se deshacen de la esclavitud del Ego. Tal vez se opera a través de tal proceso una reafirmación implícita de la composición hegemónica de esta sociedad, puesto que cada relato contiene una dimensión de moralidad fabulística. Son estos relatos, en este sentido, un formato a la vez muy antiguo y basados en las anécdotas medievales de Boccaccio o de los Fabliaux, y muy posmoder- 
no en su voluntad de deconstruir el carácter neurótico de cada miembro de una sociedad enferma por su condicionamiento histórico y sus divisiones sociales. Una nueva generación de directores cogió las riendas de esta forma de repensar el cine en Argentina para identificar estas patologías. Como lo explica Carolina Rocha, "the emergence of new directors trained in both international and domestic film schools has contributed to the diversification of themes, styles and genres" (843). Uno de los grandes jefes de fila de este movimiento es obviamente Damían Szifrón. El joven director de Relatos salvajes no sólo buscó en Almodóvar una productora sino también una inspiración de situaciones extremas y de ataques de nervios que conducen a comportamientos desmesurados, según el bien pensar de la sociedad. Como el director español, su referencia y padrino, el ar- gentino logra representar el momento de recuperación de la esencia primitiva de uno. La prensa internacional, en su gran mayoría, ha identificado en Relatos salvajes una serie de cuentos que se enfocan en la venganza y lo subraya como hilo conductor entre los capítulos. Sin embargo, aquí no se ha mencionado la dinámica de retaliación porque no es la motivación principal de los personajes, aunque lo parezca en unos relatos específicos. Es más bien el rechazo a la condición neurótica y el caer en la cuenta de su origen, generación y formación lo que empuja al personaje a un automatismo primitivo e instintivo -y por lo tanto salvaje- que le/la hace volver a una condición existencial donde predomina el Id. Y es precisamente lo que unen un acto terrorista, un homicidio, una pelea a muerte, una bomba y un orgasmo: hacen que el Ego reviente.

\section{Referencias}

Crespo-Vila, Raquel y Valeriano Piñeiro-Naval, “Del absurdo cotidiano: «Relatos salvajes», de Damián Szifrón”, Actas del III Congreso de Historia, Arte y Literatura en el Cine, Universidad de Salamanca: Salamanca, 2015, pp. 559-571.

Dupont, Joan. “History, Fantasy, and a Dog’s Life: Cannes 2014”. Film Quarterly, vol. 67, no. 4, 2014, pp. 61-66.

Ferrero, Adrián. “Relatos salvajes”. Review of Relatos salvajes. Chaqui, vol. 44, no. 2, Nov. 2015, pp. 369-371.

González, Roque, et al. Panorama Del Cine Iberoamericano En Un Contexto Global. Historias Comunes, Propuestas, Futuro. Edited by Ana Sedeño et al., 1st ed., Madrid, Dykinson, S.L., 2015.

Page, Joanna. Crisis and Capitalism in Contemporary Argentine Cinema. Durham and London: Duke University Press, 2009.

Rocha, Carolina. “Contemporary Argentine Cinema during Neoliberalism”. Hispania, vol. 92, no. 4, 2009, pp. 841-851.

Sorbille, Martín. “Echeverría y 'El Matadero’: Anticipación Del Mito Freudiano y Paternidad De La Argentina Moderna”. Iberoamericana (2001-), vol. 7, no. 25, 2007, pp. 23-42.

Žižek, Slavoj. “Tolerance as an Ideological Category”. Critical Inquiry, vol. 34, no. 4, 2008, pp. 660-682.

Žižek, Slavoj. Sobre la violencia: Seis reflexiones marginales. Buenos Aires: Paidós, 2009.

Žižek, Slavoj. “A plea for ethical violence”. Online video clip. Youtube. European Graduate School Video Lectures, February 20th 2008. Web. April 15th 2014.

Žižek, Slavoj. Living in the End Times. London and New York: Verso, 2010.

\footnotetext{
1 European Graduate School Video Lectures (Youtube).

2 “Vos te vas ya mismo de acá; no decís ni 'mu’. No sabés con quién te metiste. Te voy a sacar hasta el último centavo. Hasta la última propiedad que tu hijo puso a tu nombre para evadir al fisco, va a ser mía. Estamos casados; legalmente casa-dos. Voy a dedicar mis días a acostarme con cada persona que me tire un mínimo de onda; con todo aquel que me dé un gramito de amor. Y, cuando vos te quieras separar, voy a tomar clases de actuación para sentarme frente al juez con cara de perrito mojado y decirle que 'la estoy luchado', que 'la estoy luchando'; así nuestro matrimonio se prolonga indefinidamente. Voy a divulgar por Facebook todos tus secretos; te voy a meter el dedo en la llaga y revolverlo hasta que llores de dolor. Vas a padecer tantas humillaciones que tu única salida va ser subirte a un banquito y tirarte por el balcón. Y ahí sí; cuando la muerte nos separe, cuando ¡tu! muerte nos separe, me voy a quedar con todo" (diálogo).
} 